\title{
Dose Genital Mutilation/Cutting Impose Sexual Stress on The Prevalence Of Depression In Women
}

\author{
Mohammad-Hossein Biglu ${ }^{1 *}$ and Alireza Farnam ${ }^{2}$ \\ ${ }^{1}$ Research Center of Psychiatry and Behavioral Sciences, Tabriz University of Medical Sciences, Iran
}

Submission: October 04, 2017; Published: November 13, 2017

*Corresponding author: Mohammad-Hossein Biglu, Research Center of Psychiatry and Behavioral Sciences, Tabriz University of Medical Sciences, Iran, Email: Mh_biglu@yahoo.com

Abstract

Background: Depression is a mood related disorder that makes persistent feeling of sorrow and sadness and loss of pleasure and interest in depressed persons. The prevalence of depression in women is higher than in men. It is the main reason cause of disease-related disability among women. The current study is a cross sectional analysis that measures the depression incomes in two various groups of women living in Kurdistan province of Iran. The first group including those women, whom were circumcised and the second group, including control group.

Methods: Persian-translated version of Beck Depression Inventory-II (BDI-II) was administered among two groups of women living in Kurdistan province of Iran. The gathered data was analyzed by software package of SPSS version 23.

Results: A total number of 100 women (50 circumcised and 50 non-circumcised) participated in the study. The mean age of circumcised women was $30.6 \pm 7.51$ and the mean age of non-circumcised was $27.3 \pm 7.17$. Although the difference of depression outcomes between two groups was not significant ( $p$-value $=0.907$ ), the number of women characterized having at least mild depression among circumcised-women was greater than non-circumcised women. In addition, the measured severe depression in circumcised-women was greater than non-circumcised women $(24 \%$ versus $20 \%)$.

Conclusion: The study indicated that most of participants in the study were suffering from depression (Both groups). However, the study did not show a significance difference between the two groups of women living in the area. Though the FGM/C has negative consequences on the libido and genital behavior of women, this study showed it apparently does not have an essential impact on the women depression in the area. One may interpret this phenomenon such a way that the FGM/C either does not play important role in the depression scale of women or the depression scale of women in this area is affected with other factors such as satisfaction of life, spirituality, sexuality, aggression, intellectual issues and emotional attachments. As a result, these issues cause the women to suffer from a high prevalence of depression related to the stresses of other "planes of being" such as material, emotional, intellectual or spiritual.

Keywords: Depression, FGM, FGC, Wellbeing

\section{Introduction}

Depression is a mood related disorder that causes persistent feelings of sorrow and sadness and loss of pleasure and/or interest in depressed persons. It is the main reason cause of diseases-related disability among women. A variety number of factors play a main role in causing depression in women. One of the major causes of depression in women, which is not sufficiently considered, is the practice of genital mutilation that happens in at least 30 countries in the world.

Female mutilation is the procedure of removing the total or partial external genital organ of women for non-medical purposes. It is also called Female Genital Mutilation (FGM) or Female Genital Cutting (FGC).The history of FGM/C dates back to the early of $450 \mathrm{BC}$ that was widely done throughout ancient Egypt and in many countries and regions [1]. This procedure is widely done in Africa and in some regions in Asia, and also in Middle East. It was also seen among settlers in European countries, Australia and even in North America [2]. According to the official reports of WHO almost $98 \%$ of women aged between 15-49 in Somalia have undergone the FGM/C procedure.

The FGM/C has been considered as an illegal procedure in the USA, Australia, UK, France, European countries and also Africa countries. It is generally done before a girl has reached puberty, but differs from country to the country; sometimes the procedure is done soon after birth. Although the FGM/C is a common procedure among some Sunni Muslims, it does not have any relationship with the Quran or Islamic virtues [3]. According to the estimation of World Health Organization (WHO), approximately 130-140 million women and girls have undergone the FGM/C procedures worldwide so far. 
The FGM/C is classified in 4 main types.

a) Type 1: this is referred to clitoridectomy.

b) Type 2: is referred to the removal of clitoris and the labia minor and/or excision of the labia.

c) Type 3: this is the most invasive type and referred to the narrowing of the vaginal opening.

d) Type 4: This type includes all harmful procedures of the female genitalia for non-medical purposes [4].

The circumcised women may suffer from a lot of mental disorders e.g. anxiety, stress, PTSD, depression and etc. In this concept, we are focusing on measuring the depression scales of circumcised-women in comparison with their non-circumcised counterparts in the Kurdistan province of Iran. Depression causes the person to feel incessantly unhappiness and loss the interests and happiness. DSM-V proposed the depression as the anxiety symptoms which specify the depression as irrational worry, preoccupation with unpleasant worries, feeling tense, and difficulty relaxing, fear that something unpleasant might happen. The studies have indicated that the prevalence of depression among women is higher than men $[5,6]$.

Depression is the major component of disease burden. It was the second chief reason of disabilities in 2010 in the world [7,8]. When depression is associated with the deaths due to the suicide stock, it is considered as the third major total burden of diseases in the world [9]. It is also the main reason of disease burden in women throughout the world, which is estimated to be the foremost reason of disease burden by 2030 [10]. One of the problematic issues of women is the physical and psychological consequences of FGM/C. Many studies have indicated that FGM/C may lead to the psychological condition, e.g. the study of Masterson [11] showed that the women who have undergone the procedure of FGM/C will remember the FGM/C procedures as a painful experience and psychological disturbance that causes emotional scarring throughout their life.

This psychological disturbance of FGM/C may deeply affect the women's subconscious mind and lead to the disturbing behaviors in the future. Many girls who undergo to the FGM/C procedures, they may lose trust and confidence in their parents, care-givers and family members who aided the procedure to be done. Such experience may lead later to PTSD and other psychological problems [7]. According to the explanation of WHO [8] the FGM/C procedures have a variety of psychosomatic disorders and they may experience instability in sleep, mood, cognition disorders, depression, phobia, anxiety, phobia and low self-esteem disturbances. The death of girls was also seen due to the FGM/C procedures [9].

Our literature review showed that there has been an increase in the number of papers published in the field of FGM/C during the last decade. They mostly focused on the negative consequences of FGM/C of women health status. A study conducted by
Masterson [11] also indicated that the FGM/C women remember the procedures as a painful experience through their lifelong. A comparative study conducted by Behrendt and Moritz [12] in Senegal indicated that the mental status of circumcised women was in serious condition as compared to the non-circumcised women in the same area. Hermlund and Shell-Duncan [13] emphasized that circumcised women suffer from feelings of incompleteness, depression, anxiety, chronic irritability and even difficulty in relation with their husbands. On the other hand, most FGM/C women suffer in silence and they are unable to show their feelings and worries because that issue is taboo[14]. There is a serious need to address the psychological effects of FGM/C on the women in Iran where the psychological effect of female circumcision is still ambiguous.

\section{Materials and Methods}

This current study was carried out during a period of 3 months between September and November 2016 in Kurdistan province of Iran. The samples of study consisted of 50 circumcised and 50 uncircumcised women. They were selected through their referring to the health-care centers in Kurdistan province of Iran. Beck Depression Inventory II (BDI-II) was used for gathering the data. The BDI-II is an authentic self-reported screening tool for measuring the depression scale [15]. It is widely used for calculating the presence and severity of depression. The BDI-II consists of 21 items.

Each item explains a particular behavioral appearance of depression and scored 4-points ranging from 0 to 3 . In accordance to the guidelines of BDI-II, we interpreted the BDIII as: minimal ranging from $0-13$, mild depression ranging between14-19, moderate depression ranging between 20-28, and severe depression ranging between 29-63. We are aware that depression is the main reason of many disease-related disabilities among women. The Epidemiological investigations have indicated that the lifetime prevalence of a major-depressive disorder among women is roughly two times greater than men [16]. Therefore, the accurate measurement of depression among ethnic minorities, especially in women with FGM/C, will be an important task.

\section{Results}

A total number of 100 women participated in the study and completed the BDI-II. (Table 1) shows the demographic characteristics of circumcised and non-circumcised women, including age, education level, employment status, incomes and residence status. As shown in (Table 1) the mean age of participated FGM/C and non-FGM/C were $30.6 \pm 7.51$ and $27.3 \pm 7.17$ respectively, ranging from $12-46$ years old, with a significant difference between the two groups.

Regarding to the $\mathrm{FGM} / \mathrm{C}$ procedures, $52 \%$ of them was done before 3 years of age. The majority of FGM/C women had only elementary education (30\%), almost $30 \%$ of them were employed. Regarding to the economic status of participants 


\section{Psychology and Behavioral Science International Journal}

$80 \%$ had moderate or low income, whereas only $10 \%$ of them had high income. More than half of them (56\%) were residents in rural areas. Regarding to the depression outcomes of participated women, they were characterized in 4 groups (Table $2)$. Ten (20\%) of FGM/C women were characterized as having no depressive symptoms, 13 (26\%) of them characterized with mild depressive symptoms, 15 (30\%) of them with moderate depressive symptoms and 12 (24\%) of them were characterized as having the severe depressive symptoms. In other words, $80 \%$ of circumcised women characterized as having at least mild depression, and $24 \%$ of them had severe depression; whereas $74 \%$ of non-circumcised women characterized as having at least mild depression, and $20 \%$ of them showed having severe depression. It is clear that depression was found among small groups of women in the area.

Table 1: Demographic characteristics of participants $(n=100)$.

\begin{tabular}{|c|c|c|c|}
\hline Variable & Circumcised women $(n=50)$ & Non-circumcised women $(n=50)$ & p-Value \\
\hline Age (years) & $30.6 \pm 7.51$ & $27.3 \pm 7.17$ & $0.000 *$ \\
\hline \multicolumn{4}{|l|}{ Age at FGM/C } \\
\hline 1-3 years & $26(52 \%)$ & - & \\
\hline $4-6$ years & $13(26 \%)$ & - & \\
\hline 7-9 years & $11(22 \%)$ & - & \\
\hline Educational level & & & $0.000 *$ \\
\hline Illiterate & $15(30 \%)$ & $7(14 \%)$ & \\
\hline Primary school & $20(40 \%)$ & $9(18 \%)$ & \\
\hline High school & $11(22 \%)$ & $15(30 \%)$ & \\
\hline Diploma \& higher & $4(8 \%)$ & $19(38 \%)$ & \\
\hline \multicolumn{4}{|l|}{ Employment status } \\
\hline housewife & $35(70 \%)$ & $22(44 \%)$ & \\
\hline employed & $15(30 \%)$ & $28(56 \%)$ & \\
\hline Income & & & $0.000 *$ \\
\hline Low & $22(44 \%)$ & $16(32 \%)$ & \\
\hline Moderate & $18(36 \%)$ & $16(32 \%)$ & \\
\hline High & $10(20 \%)$ & $18(36 \%)$ & \\
\hline Residence & & & $0.000 *$ \\
\hline Rural & $28(56 \%)$ & $24(48 \%)$ & \\
\hline Urban & $22(44 \%)$ & $26(52 \%)$ & \\
\hline
\end{tabular}

${ }^{*} p$-Value is significant at less than 0.05 levels.

Table 2: Depression outcomes in circumcised and non-circumcised women $(n=100)$.

\begin{tabular}{|c|c|c|}
\hline Variable & Circumcised women (n=50) & Non-circumcised women (n=50) \\
\hline No depression(0-13) & $10(20 \%)$ & $13(26 \%)$ \\
\hline Mild depression (14-19) & $13(26 \%)$ & $14(28 \%)$ \\
\hline Moderate depression (20-28) & $15(30 \%)$ & $13(26 \%)$ \\
\hline Severe depression (29-63) & $12(24 \%)$ & $10(20 \%)$ \\
\hline
\end{tabular}

P-value $=0.907$

\section{Discussion}

Analysis of data indicated that the demographic profiles between the two groups were significantly different.

The FGM/C women were generally older than non-FGM/C women, and their education levels were lower than nonFGM/C women. The FGM/C women were more likely to be married younger than non-FGM/C women, and more likely to be housewives, unemployed, and resident in rural areas compared non-FGM/C women. The Beck Depression Inventory
II was used to measure and compare the depression scales of the two groups of circumcised and non-circumcised women. Although the difference of depression scales between the two groups was not significant ( $p$-value $=0.907$ ), but the number of women characterized having at least Mild depression among circumcised-women was greater than non-circumcised women. On the other hand, the calculated severe depression in circumcised-women was also greater than that for noncircumcised women (24\% versus $20 \%)$. 
The socioeconomic condition of both groups indicated that they were in stressful conditions; however, $80 \%$ of FGM/C and $60 \%$ of non-FGM/C women had moderate to low incomes, whereas only $10 \%$ and $18 \%$ of them had economically high incomes respectively. It is remarkable that the socioeconomic status of people seems to have a strong relationship with mental depression. The study of Santos and colleagues has emphasized on the association between mental depression and the socioeconomic nature of individuals [17]. The similarity of depression scales among the two groups of women in the area indicated that the women in this area might have similar socio-economic problems in their daily lives; therefore, the socioeconomic conditions of their environment possibly result in similar mental health problems, like depression.

As a result, the FGM/C procedures do not seem to be the main cause of the depression of women in the area, other factors should be associated with the depression scales of these women. According to Robert C. Cloninger a variety of factors may influence the wellbeing of human. He categorizes the human thought content into five streams which he called as «planes of being». Cloninger believes human thought varies widely in content, flowing across five planes, each plane is related to human's evolutionary problems and preoccupations

There are five planes of being;

Sexual plane», related to concerns about reproduction and sexuality.

Material plane», related to concerns about power and possession.

Emotional plane», related to concerns about emotional bonds and attachments.

Intellectual plane», related to concerns about communication and culture.

Spiritual plane», related to understanding what is beyond individual human existence.

Human stresses are related to one of the above mentioned planes and the events and conflicts in each plane can impact human mental state [18]. Our study showed that one of the biggest stresses in sexual plane (ie. Genital mutilation/ cutting) cannot impact the occurrence of depression in women contributing in this study and can be evidence that the stresses of higher planes (like material, emotional, etc.) can have more impact role in formation of depression in women.

\section{Conclusion}

A small selected population of circumcised and noncircumcised women from the Kurdistan province of Iran indicated that although the level of depression was higher among circumcised women than the depression in non-circumcised women, there were not significant differences between the two groups. This phenomenon may have been due to the similar social problems, as wells as mental disturbances among them. Although the FGM/C has negative consequences on the sexual desire and genital behavior of women, apparently it does not exert an essential impact on the women depression in the area. One may interpret this phenomenon in a way that the FGM/C either does not play an important role in the depression scale of women, or the depression scale of women in this area is higher due to other factors that cause the women to suffer from depression. Robert C Cloninger [19] emphasized that many factors might influence on the human interpersonal relationships during their ordinary daily life, including satisfaction of life, spirituality, sexuality, aggression, intellectual issues and emotional attachments. As a result, these issues may have caused women in this area to suffer from high levels of depression. The last point is that the planesof-being are systematically associated with depression and the most human emotions.

\section{Acknowledgment}

The authors would like to thank all people who participated in the study.

\section{Authors Contribution}

All authors contributed to this work.

\section{Ethic Approval}

The ethical committee of research affairs of Tabriz University of Medical Sciences has approved the current study.

\section{References}

1. Barstow DG (1999) Female genital mutilation: the penultimate gender abuse. Child abuse \& neglect 23(5): 501-510.

2. (2017) Female genital mutilation.

3. Vloeberghs E, Van der Kwaak A, Knipscheer J, Van den Muijsenbergh M (2012) Coping and chronic psychosocial consequences of female genital mutilation in The Netherlands. Ethnicity \& health 17(6): 677695.

4. Mohammad Hossein Biglu, Alireza Farnam, Parvaneh Abotalebi, Sahar Biglu, Mostafa Ghavami (2016) Effect of female genital mutilation/ cutting on sexual functions. Sexual \& Reproductive Healthcare 10: 3-8.

5. Cyranowski JM, Frank E, Young E, Shear MK (2000) Adolescent onset of the gender difference in lifetime rates of major depression: a theoretical model. Arch Gen Psychiatry 57(1): 21-27.

6. Ford DE, Erlinger TP (2004) Depression and C-reactive protein in US adults: data from the Third National Health and Nutrition Examination Survey. Arch Intern Med 164(9): 1010-1014.

7. Harvey A Whiteford, Louisa Degenhardt, Jurgen Rehm, Amanda J Baxter, Alize J Ferrari, et al. (2013) Global burden of disease attributable to mental and substance use disorders: findings from the Global Burden of Disease Study. The Lancet 382: 1575-1586.

8. Murray CJ, Atkinson C, Bhalla K, Birbeck G, Burstein R, et al. (2013) The state of US health, 1990-2010: burden of diseases, injuries, and risk factors. JAMA 310(6): 591-608.

9. Ferrari AJ, Norman RE, Freedman G, Baxter AJ, Pirkis JE, et al. (2014) The burden attributable to mental and substance use disorders as risk factors for suicide: findings from the Global Burden of Disease Study 2010. PLoS ONE 9(4): e91936. 
10. WHO (2004) The global burden of disease WHO Press, Geneva, Switzerland.

11. Masterson JM, Swanson JH (2000) Female genital cutting: breaking the silence enabling change. Eldis

12. Behrendt A, Moritz S (2005) Posttraumatic stress disorder and memory problems after female genital mutilation. American Journal of Psychiatry 162(5):1000-1002.

13. Ylva Hernlund, Bettina Shell Duncan (2007) Transcultural positions: negotiating rights and culture. Transcultural bodies: Female genital cutting in global context 1-45.

14. Berg, Rigmor C, Denison, Eva, Fretheim, Atle (2010) Psychological, social and sexual consequences of female genital mutilation/cutting (FGM/C): a systematic review of quantitative studies. Report from Kunnskapssenteret (Norwegian Knowledge Centre for the Health Services)
15. Aaron T Beck, Robert A Steer, Margery G Carbin (1988) Psychometric properties of the Beck Depression Inventory: Twenty-five years of evaluation. Clinical psychology review 8(1): 77-100.

16. Noble, Rudolf E (2005) Depression in women. Metabolism 54(5): 49 52.

17. Marcelo Justus dos Santos, Henrique Coelho Kawamura, Ana Lucia Kassouf (2012) Socioeconomic conditions and risk of mental depression: An empirical analysis for Brazilian citizens. Economics Research International 2012(2012): 1-16.

18. Benjamin Sadock,|Virginia Alcott Sadock,| Pedro Ruiz (2009) Kaplan And Sadock's Comprehensive Textbook of Psychiatry $9^{\text {th }}$ Edn, Williams \& Wilkins Press, Lippincott, New York, USA

19. C Robert Cloninger (2004) Feeling good: the science of well-being Oxford University Press, UK.

\section{Your next submission with Juniper Publishers will reach you the below assets}

- Quality Editorial service

- Swift Peer Review

- Reprints availability

- E-prints Service

- Manuscript Podcast for convenient understanding

- Global attainment for your research

- Manuscript accessibility in different formats

( Pdf, E-pub, Full Text, Audio)

- Unceasing customer service

Track the below URL for one-step submission https://juniperpublishers.com/online-submission.php 